\title{
O CONSTRUTIVISMO COMO DISCURSO PEDAGÓGICO OFICIAL NA REDE DE ENSINO PAULISTA A PARTIR DA DÉCADA DE 1980
}

\author{
Ana Carolina Galvão Marsiglia1 \\ Universidade Federal do Espírito Santo
}

\section{RESUMO}

O construtivismo é a concepção pedagógica oficialmente adotada pela Secretaria de Estado da Educação de São Paulo (SEE) desde 1983. O Estado de São Paulo é o principal centro econômico brasileiro e tem a maior população do país. A rede estadual de ensino paulista administra mais de 200 mil professores, quatro milhões de alunos e cinco mil escolas. $\mathrm{O}$ número de alunos sob responsabilidade da SEE é maior que a população de quinze Estados brasileiros. Diante desses números e dos baixos resultados que o Estado tem alcançado em diferentes avaliações, verifica-se a importância de se examinar o referencial pedagógico assumido pela Secretaria a partir da década de 1980. Assim, o objetivo desse artigo é trazer, à luz da pedagogia histórico-crítica, algumas considerações sobre documentos publicados pela SEE durante os governos que se sucederam de 1983 a 2010 que ilustram como o construtivismo se instaurou e se mantém nas sucessivas administrações paulistas e suas implicações para a formação humana plena. O que pudemos analisar nos documentos da SEE é sua filiação a uma concepção teórica que mantém vínculos com o neoliberalismo e pós-modernismo, que em lugar de possibilitar a apropriação da riqueza material e intelectual humana, ocasiona a preparação do indivíduo para a exploração capitalista, impedindo o desenvolvimento máximo de suas potencialidades.

Palavras-chave: Construtivismo, Pedagogia histórico-crítica, Secretaria de Estado da Educação de São Paulo.

\section{CONSTRUCTIVISM AS AN OFFICIAL PEDAGOGICAL DISCOURSE IN THE EDUCATION NETWORK OF SÃO PAULO SINCE THE 1980S}

\begin{abstract}
Constructivism is the pedagogical conception that has been officially adopted by the São Paulo State Department of Education (SEE) since. The state of São Paulo is the main economic center in Brazil and it has the largest population in this country. The state education network of São Paulo manages over 200 thousand teachers, 4 million students, and 5 thousand schools. The number of students that SEE is responsible for is higher than the population of fifteen Brazilian states. In face of these numbers and the poorest results that this state has achieved in different types of assessment, we can see the importance of examining the pedagogical reference adopted by the department in the 1980s. Therefore, based on historical-critical pedagogy, this article aims at analyzing documents published by SEE during the governments succeeding between 1983 and 2010, which show how constructivism was adopted and kept in the succeeding managements in São Paulo, as well as its consequences to complete human formation. What we could see in the SEE's documents is their connection to a theoretical concept bonded to Neoliberalism and Postmodernism, which, instead of enabling the appropriation of human material and intellectual wealth, prepares individuals for capitalist exploitation, hindering their maximum potentialities.

Keywords: Constructivism, Historical-critical Pedagogy, São Paulo State Department of Education.
\end{abstract}




\section{Introdução}

O Ministério da Educação (MEC) elaborou em 2007 uma análise comparada dos resultados de proficiência dos estudantes entre 1995 e 2005, avaliados pelo Sistema Nacional de Avaliação da Educação Básica (SAEB). Os índices da $4^{\mathrm{a}}$ série do ensino fundamental, indicaram que a proficiência em língua portuguesa caiu de 188 pontos (1995) para 172 pontos (2005). Se observarmos os resultados da $8^{\text {a }}$ série, poderemos verificar uma queda de 256 pontos (1995) para 232 pontos (2005) e na $3^{\text {a }}$ série do ensino médio, a pontuação reduz de 290 para 258 pontos (BRASIL, 2007). Podemos concluir que, ao longo da década analisada por este sistema, os resultados não só pioraram, como também ao longo da escolarização as insuficiências foram se agravando, gerando pontuações cada vez mais diferentes (na $4^{\mathrm{a}}$ série a redução foi de 16 pontos em dez anos, enquanto no $3^{\circ}$ ano do ensino médio foram 32 pontos).

$\mathrm{Na}$ avaliação do Programa Internacional de Avaliação de Alunos (PISA2, na sigla em inglês) de 2006, entre 57 países avaliados, o Brasil ficou em $52^{\circ}$ lugar, sendo que conforme noticiou o site "Todos pela Educação", em 5 de dezembro de 2007, o Estado de São Paulo teve médias piores que as nacionais em leitura e ciências e média igual à nacional em matemática. "Reunindo, sozinho, cerca de $20 \%$ dos alunos do País, a média paulista, na verdade, chega a puxar para baixo a média nacional, segundo o MEC." (PARAGUASSÚ, 2007, s/p).

No Pisa de 2009, com resultados divulgados em 2010, o Brasil ficou com a $53^{\text {a }}$ posição entre 65 economias do mundo, sendo que dos vinte mil estudantes brasileiros avaliados, mais da metade teve a nota mais baixa de desempenho, o nível 1. Entre os Estados brasileiros, São Paulo ficou atrás do Distrito Federal, Santa Catarina, Rio Grande do Sul, Minas Gerais, Paraná e Espírito Santo. Como noticiou o site "Todos pela Educação",

Os resultados da avaliação por Estados feita pelo Ministério da Educação com base nos dados do Pisa 2009 mostram que São Paulo subiu do $11^{\circ}$ para o $7^{\circ}$ lugar entre as 27 unidades da federação. Se não é tão ruim quanto há três anos, quando perdia para Estados como Paraíba e Sergipe, o resultado está longe de refletir o poderio econômico paulista. (PARAGUASSÚ; MANDELLI, 2010, s/p).

No Estado de São Paulo, em 2005 o Índice de Desenvolvimento da Educação Básica (IDEB), foi de 4,7, subindo para 5,0 em 2007 e para 5,5 em 2009. Se à primeira vista isso poderia parecer um ganho e melhora da aprendizagem dos alunos, uma análise mais aprofundada nos mostra que não é bem assim. Nossos índices têm prospecção de aumento bastante lento (17 anos para se atingir o patamar 6,0), o sistema de ciclos diminui as taxas de reprovação, interferindo nos resultados desse indicador e a maioria das unidades escolares tem preparado seus alunos para as provas, o que significa que as avaliações não mensuram corretamente o processo de ensino e aprendizagem das escolas. Segundo Apolinário (2010, s/p) se os resultados fossem baseados na realidade das escolas, veríamos números bem piores. Para o autor,

[...] o Ideb, como muitos outros dados quantitativos apresentados pelo governo federal para a educação, é apenas uma maquiagem, pois os alunos continuam saindo do $5^{\circ}$ ano sem saber ler e escrever direito e sem 
executar, na prática, as noções básicas das quatro operações matemáticas.(APOLINÁRIO, 2010, s/p).

O Estado de São Paulo é o principal centro econômico brasileiro e tem a maior população do país. A rede estadual de ensino paulista administra mais de 200 mil professores, quatro milhões de alunos e cinco mil escolas. O número de alunos sob responsabilidade da Secretaria de Estado da Educação de São Paulo (SEE) é maior que a população de quinze Estados brasileiros. Diante desses números e dos baixos resultados que o Estado tem alcançado em diferentes avaliações, verifica-se a importância de se examinar o construtivismo como referencial pedagógico da política educacional do Estado de São Paulo desde 1983.

Para desenvolvermos essa análise, adotamos como referencial teórico a pedagogia histórico-crítica e, nesse sentido, uma de nossas premissas é a de que a formação humana que garanta aos indivíduos o desenvolvimento máximo de suas possibilidades não poderá ser alcançada por meio de uma educação calcada em pressupostos teóricos que submetem os seres humanos à ordem do capital.

Diversos são os trabalhos que nos auxiliam a compreender a política educacional, seja em âmbito nacional ou paulista, incluindo questões como o sistema de ciclos, programas e projetos implementados por diferentes gestões visando a melhoria do ensino, jornada de trabalho docente, atuação de profissionais do ensino nas redes educacionais, programas de formação docente, as reformas a que foi submetida a educação desde a década de 1980 e implicações da política educacional para o planejamento escolar3. Entretanto, nesses estudos não encontramos discussões específicas sobre a concepção pedagógica oficial da SEE ou uma análise que, em um mesmo trabalho, inclua todos os governos pós-64. Daí nosso intento de contribuir para desvelar a política educacional paulista nas diferentes administrações que se sucederam desde 1983, no que se refere à adoção do construtivismo.

Ainda devemos ressaltar que concordamos com Duarte (2006b, p. 97), quando afirma que boa parte das atividades realizadas em programas de pós-graduação não tem se voltado à finalidade de contribuir " [...] para o processo de universalização da propriedade do conhecimento científico, artístico e filosófico por meio da universalização da escola pública, gratuita e laica". Segundo ele, as pesquisas deveriam manter compromisso político e ético com a formação de intelectuais críticos e indica três tipos de pesquisa que julga contribuírem para esse propósito:

[...] aquelas voltadas para a construção de um discurso pedagógico afirmativo sobre a transmissão de conhecimentos na escola; aquelas voltadas para a elaboração de análises críticas das pedagogias subsumidas ao universo ideológico neoliberal e pós-moderno e aquelas voltadas para o desenvolvimento de análises críticas da realidade educacional na sociedade contemporânea. (DUARTE, 2006b, p. 98).

Nesse sentido, nos posicionamos afirmativamente em relação à pedagogia histórico-crítica e visamos colaborar com outros estudos desenvolvidos na perspectiva marxista4, o que revela que nossa preocupação em analisar expressões de pedagogias ligadas ao neoliberalismo e pós-modernismo não é um caso isolado, mas parte de um esforço coletivo que vem sendo realizado com o propósito de construir uma pedagogia 
marxista, que possa enfrentar os desafios postos pela prática educativa alienada com a qual nos deparamos na atualidade.

Destarte, o objetivo desse artigo é trazer algumas das considerações feitas em nossa tese de doutorado (MARSIGLIA, 2011), ilustrando com documentos da SEE publicados desde 1983, como o construtivismo se instaurou e se mantém nas sucessivas administrações paulistas. Iniciaremos com algumas linhas sobre as pedagogias do "aprender a aprender", que tem o construtivismo como uma de suas expressões. Em seguida, nos debruçaremos sobre as administrações de Montoro, Quércia, Fleury, Covas, Alckmin e Serra, discutindo algumas implicações da adoção desse referencial teórico para a formação humana.

\section{As pedagogias do "aprender a aprender"}

As pedagogias do "aprender a aprender" têm se firmado hegemonicamente, sendo diferentes discursos (construtivismo, pedagogia das competências, pedagogia de projetos, teoria do professor reflexivo etc.) variantes de uma mesma concepção.

O universo ideológico ao qual estão ligadas essas pedagogias é o neoliberalismo5 e o pós-modernismo6 e elas exercem forte influência sobre o pensamento pedagógico contemporâneo. O discurso das pedagogias do "aprender a aprender" segundo o qual elas estariam voltadas às necessidades de uma nova sociedade, esconde um processo de acentuação da divisão de classes, uma vez que essas pedagogias não propõem a superação do capitalismo e consequentemente, conduzem a relação educação e sociedade de forma idealista.

As pedagogias do "aprender a aprender", por negarem a função do trabalho educativo de transmissão de conhecimento, que caracteriza a especificidade da educação escolar, acabam por defender uma visão equivocada do que seja uma escola democrática. O carro-chefe das pedagogias do "aprender a aprender" vem sendo, nas últimas décadas, o construtivismo, que de acordo com Duarte, não é algo independente do contexto mundial. Para o autor,

Tal movimento ganha força justamente no interior do aguçamento do processo de mundialização do capital e de difusão, na América Latina, do modelo econômico, político e ideológico neoliberal e também de seus correspondentes no plano teórico, o pós-modernismo e o pósestruturalismo. (DUARTE, 2006b, p. 30),

O construtivismo, segundo Rossler (2000, p. 7):

[...] constitui-se num ideário epistemológico, psicológico e pedagógico, fortemente difundido no interior das práticas e reflexões educacionais e, a despeito das divergências que possam existir quanto ao que seriam as principais características definidoras desse ideário em educação, não poderíamos negar a existência dessa corrente, pelo simples fato do grande número de publicações de autores autodefinidos como construtivistas.

Segundo Duarte (2006b), o lema "aprender a aprender" não significa, como poderia parecer à primeira vista, a defesa de uma educação escolar que fomente a criatividade e a autonomia intelectual em oposição a uma educação pautada na reprodução mecânica de 
conteúdos e na heteronomia. O lema "aprender a aprender" conteria, segundo o citado autor, uma atitude fundamentalmente negativa em relação à educação escolar. Tal atitude seria caracterizada por quatro princípios compartilhados pelas pedagogias do "aprender a aprender": 1) a aprendizagem que ocorra sem a transmissão intencional do conhecimento terá maior valor educativo; 2) o processo de aquisição ou construção do conhecimento tem mais valor do que o conhecimento em si mesmo; 3) uma atividade será verdadeiramente educativa somente quando for espontaneamente desencadeada e conduzida pelas necessidades e interesses dos alunos; 4) a escola deve ter por principal objetivo desenvolver uma alta capacidade de adaptação social nos indivíduos. Cada um desses princípios contém um acento de valor negativo em relação ao que Saviani (2003) caracterizou como os aspectos clássicos na educação escolar. Podemos observar esses princípios de caráter negativo sobre a educação escolar nos documentos da SEE, como veremos a seguir.

\section{O governo Montoro}

André Franco Montoro, primeiro governador eleito pelo voto direto após o regime militar, administrou o Estado de São Paulo de 1983 a 1987 e sua principal ação para a educação no tocante à concepção pedagógica foi a implantação do Ciclo Básico (CB). Ele instaurava a promoção automática dos alunos da $1^{\mathrm{a}}$ para a $2^{\mathrm{a}}$ série e visava, conforme se lê no Artigo $1^{\circ}$ de seu decreto:

I - assegurar ao aluno o tempo necessário para superar as etapas de alfabetização, segundo seu ritmo de aprendizagem e suas características sócio-culturais;

II - proporcionar condições que favoreçam o desenvolvimento das habilidades cognitivas e de expressão do aluno previstas nas demais áreas do currículo;

III - garantir às escolas a flexibilidade necessária para a organização do currículo, no que tange ao agrupamento de alunos, métodos e estratégias de ensino, conteúdos programáticos e critérios de avaliação do processo de ensino-aprendizagem. (SÃO PAULO, 1983a).

É nesse momento que o ideário construtivista ganha espaço no Estado de São Paulo, pois é tomado como concepção pedagógica a ser adotada pela rede de ensino, dirigindo-se pelos mencionados princípios formulados no Artigo $1^{\circ}$ do decreto $\mathrm{n}^{\mathrm{o}} 21.833$ de 28/12/1983 (SÃO PAULO, 1983a): flexibilidade, respeito à individualidade e às características sócio-culturais dos alunos. A implantação do Ciclo Básico, tendo por base o construtivismo, visava um "[...] projeto de reorganização curricular, que tinha como escopo orientar um ensino mais adequado ao aluno concreto que frequentava a escola pública." (DURAN; ALVES; PALMA FILHO, 2005, p. 90, grifo nosso).

Apesar de ter seu decreto expedido em dezembro de 1983 e respectiva resolução sobre suas normas publicado em janeiro de 1984, o CB não se referia a um projeto repentino e sem fundamentos. Ao contrário, tratava-se de um intento planejado cuidadosamente durante o primeiro ano do governo de Montoro, o que pode ser observado, por exemplo, por meio dos seguintes documentos: a coletânea "Capacitação de recursos humanos para o ensino de $1^{\circ}$ grau" (SÃO PAULO, 1983b) e o artigo "Uma proposta 
didática para alfabetização de crianças das classes populares." (CRAIDY, GROSSI e FIALHO, 1983).

O primeiro documento é uma coletânea preparada para um programa de formação de monitores em alfabetização, com material impresso composto por textos de diferentes autores, anteriormente publicados em forma de artigos de revistas especializadas ou como capítulos de livros. Em todos os artigos inseridos na coletânea, uma "nova concepção de educação" (construtivista) é apresentada como revolucionária e finalmente, a solução para os problemas do fracasso escolar (evasão e repetência) que se observava em altos índices naquele momento. A tônica dos textos é de valorização da cultura local em detrimento de conhecimentos universais e a atitude espontânea dos alunos como mais importante do que a transmissão do conhecimento pelo professor.

Para ilustrar, podemos mencionar o texto de Regina Leite Garcia que faz parte dessa coletânea da SEE, denominado "A qualidade comprometida e o compromisso da qualidade" (GARCIA, 19827), no qual a autora faz críticas ao professor como agente do ensino, como se seu papel de ensinar fosse, além de distante das necessidades dos indivíduos, despótico e impositivo:

\begin{abstract}
O aluno não é sujeito do conhecimento. Conhecimento é o da escola, o do professor que tem o poder de decidir o que deve ser ensinado, o que é importante ser aprendido, sem ser levado em consideração o que para o aluno é significativo, o que lhe facilitará resolver as situações desafiadoras que a vida constantemente lhe coloca, o que poderá ser útil para sua libertação [...]. Esse conhecimento, autoritariamente imposto, dissociado de sua realidade objetiva é apresentado como bom e certo e o que ele tem [o aluno], a partir de sua vivência não é reconhecido, logo não é bom, não é importante. (GARCIA, 1982, p. 52).
\end{abstract}

Tem-se aqui a presença de um dos princípios valorativos das pedagogias do "aprender a aprender" que apresentamos na introdução desse artigo, qual seja, a apreciação negativa do ensino como transmissão de conhecimento do professor para o aluno.

$\mathrm{O}$ outro documento que mencionamos é o artigo "Uma proposta didática para alfabetização de crianças das classes populares" (CRAIDY, GROSSI e FIALHO, 1983), publicado pela "Revista Brasileira de Estudos Pedagógicos", de autoria de membros do Grupo de Estudos sobre o Ensino da Matemática de Porto Alegre (GEEMPA), que trazia uma discussão sobre as pesquisas efetuadas por ele nos anos de 1979 a 1982, fundamentadas em Piaget e Emília Ferreiro

[...] com o objetivo de construir uma proposta didática integrada para a alfabetização de crianças das periferias urbanas [...] [buscando demonstrar que] não é a classe social, em si mesma, a responsável pelos atrasos escolares destas crianças. (CRAIDY, GROSSI e FIALHO, 1983, p. 209).

As autoras do artigo, ao defenderem que a classe social não é determinante na aprendizagem do indivíduo, baseiam sua proposta

[...] na construção do conhecimento (no sentido piagetiano), na motivação autônoma (prazer de aprender), na recuperação das atividades manuais e 
corporais para o trabalho didático e pedagógico, na ligação indissociável entre criatividade e cognição, na vinculação da aprendizagem às experiências e vivências concretas das crianças, e na intensificação da comunicação e das interações entre os alunos (troca entre iguais), com a inevitável consequência que isto acarreta: uma transformação das relações professor-aluno. (CRAIDY, GROSSI e FIALHO, 1983, p. 210).

Essas colocações explicitam a concepção construtivista adotada pelo grupo gaúcho e suas vinculações aos preceitos das pedagogias do "aprender a aprender": espontaneidade da aprendizagem, o processo de aquisição de conhecimentos ligado às experiências dos indivíduos e a desvalorização da transmissão do conhecimento. Vale ressaltar que os estudos do GEEMPA foram sistematicamente incorporados às publicações da Coordenadoria de Estudos e Normas Pedagógicas (CENP - órgão da SEE) a partir de 1985, quando a Secretaria, já com o CB implantado, passou a apresentar propostas didáticas de alfabetização construtivista, o que se manteve em toda a gestão, ampliando-se para outras áreas de conhecimento, isto é, não se restringiu a princípios para a alfabetização.

\section{O governo Quércia}

O sucessor de André Franco Montoro foi Orestes Quércia, eleito para o período de 1987 a 1991. O novo governador era vice de Montoro na gestão anterior e manteve o programa do Ciclo Básico, que ganhou novas dimensões com a implantação do Programa de Jornada Única Docente e Discente, que visava requalificar a escola pública no prazo de dez anos, sendo que para tanto era necessário melhorar as condições do Ciclo Básico, de forma a garantir uma expansão no tempo de permanência do aluno na escola e a dedicação exclusiva do professor ao CB.

No que tange à concepção pedagógica, o governo Quércia não efetuou alterações de linha teórica. Em outras palavras, o construtivismo se manteve como fundamento da SEE. Destaque desse governo foi a implantação das propostas curriculares das diferentes áreas de conhecimento, que vinham sendo discutidas desde a gestão de Montoro, todas apoiadas em bases construtivistas.

Nos documentos desse período (e de outros), podemos notar que o professor é seduzido pelo conteúdo dos textos, pois há um clima de felicidade, prazer e deslumbramento com a proposta construtivista. Por exemplo, no texto "Alfabetização: uma nova didática? Relatos de professores sobre a implantação do $C B$ e sua concepção teórica", publicado em 1987, ressalta-se a importância de o professor estudar, se dedicar, assumir seus erros, se maravilhar com as conquistas, aceitar a espera pela aprendizagem de seus alunos etc. A professora Cleide, de Campinas (as entrevistadas são identificadas somente pelo primeiro nome e cidade), afirma ter ficado tão entusiasmada com o construtivismo, "[...] que este ano quero entrar direto neste tipo de trabalho, mudar meu comportamento, meu sistema, meu trabalho...tudo." (SÃO PAULO, 1987, p. 37).

Na publicação "Ciclo básico em jornada única", de 1988, Telma Weisz, no texto "As contribuições da psicogênese da língua escrita e algumas reflexões sobre a prática educativa de alfabetização" assevera que conhecer consistentemente o que ensina é importante para o papel mediador do professor. Sua defesa é a da reflexão sobre a prática, como podemos constatar quando a autora afirma que a atuação do professor 
[...] depende fundamentalmente [de sua disposição] para estudar; o mediador precisa construir sua competência para planejar e implementar situações de aprendizagem. Para construir esta competência, o único caminho é o da reflexão sobre a prática. (WEISZ, 1988, p. 42).

Afirmações como estas vistas anteriormente, dão ao professor a responsabilidade pelo sucesso de seus alunos. Entretanto, isso não deriva de um processo relacionado à teoria pedagógica que o orienta e sim, ao seu esforço pessoal para atingir tais resultados, pois para o construtivismo, o professor não tem papel central. Como assevera Becker (1993, p. 71, grifo do autor):

\begin{abstract}
Quando um professor ensina um conteúdo aos seus alunos [...], ele atravessa todo o processo de construção do conhecimento obstruindo o processo de abstração reflexionante. Em nome da transmissão do conhecimento ele impede a construção das estruturas básicas de todo o conhecer, o a priori de toda a compreensão. É isto que Piaget quer dizer ao afirmar que toda vez que ensinamos algo à criança, impedimos que ela invente esta e tantas outras coisas.
\end{abstract}

Voltando aos relatos de professores apresentados na publicação de 1987 já referida, observa-se que são todos muito positivos. Quando não, se referem à crítica dos professores aos colegas que não aderiram à onda construtivista. Em nenhum momento se faz uma discussão sobre a desvalorização do profissional em questão, tratado como incompetente por não trabalhar segundo esta concepção teórica; tão pouco se trata do adoecimento docente advindo da internalização dessa incompetência; menos ainda são discutidos ou ao menos mencionados os insucessos do construtivismo.

No relato da professora Luiza (São Paulo), ela afirma que as crianças "[...] estão conscientes de que a aprendizagem vai ocorrer, que depende de vontade e espera, mas que o dia de todos chegará." (SÃ̃O PAULO, 1987, p. 36). Essa afirmação mostra uma concepção na qual o processo de ensino está totalmente separado do conteúdos do conhecimento e de sua aprendizagem. Dessa forma, coerentemente com os postulados construtivistas, por um lado se impede os indivíduos de se apropriarem do patrimônio humano genérico, consolida-se a naturalização das classes sociais e por outro, desvalorizase o professor e atribui-se ao indivíduo a responsabilidade por seu sucesso ou fracasso. Por isso Martins (2004, p. 65) afirma que deixar o conteúdo da aprendizagem em segundo plano "[...] em nome de um apologético 'aprender a aprender' [...]" significa dar ao processo educativo conotações subjetivas, cujo resultado será " [...] a individualização do conhecimento, a naturalização das desigualdades e a cruel responsabilização do indivíduo por aquilo que suas condições objetivas de vida não lhe permitiram, no que se inclui uma educação escolar de qualidade".

\title{
O governo Fleury
}

Luis Antônio Fleury Filho, secretário de segurança pública da gestão anterior, assume a administração paulista no período de 1991 a 1994, completando um período de 12 anos de hegemonia do Partido do Movimento Democrático Brasileiro (PMDB) à frente do governo do Estado. 
Essa administração implantou o "Programa de Reforma do Ensino Público de São Paulo", por meio do qual chega ao campo educacional o quadro referencial da Qualidade Total, "[...] adotado como parâmetro de qualificação da produção na indústria em escala mundial" (NÓBREGA, 1999, p. 54), que ocultava a influência das agências externas (Banco Mundial e CEPAL8) sobre o governo, A "reforma", portanto, afirmava visar uma maior autonomia da escola, mas centralizou na cúpula do poder as medidas administrativas que a implementariam (CARVALHO, 1999). Foi justamente nesse contexto que se implementou a "Escola Padrão", referindo-se a adoção de um padrão de qualidade que corresponderia "[...] à negação da escola uniforme, burocrática, rígida e anônima, padronizada." (NÓBREGA, 1999, p. 62-63). A propositura era que durante o governo Fleury a Escola Padrão atingisse paulatinamente toda a rede de ensino. Contudo,

[...] o projeto existiu durante apenas três anos, sendo desativado logo no início de 1995. Consideramos o período muito curto para sua avaliação no campo pedagógico, no processo ensino aprendizagem, até porque apenas 306 unidades escolares viveram a caminhada do projeto por três anos, outras 1052 unidades vivenciaram por dois anos e 256 por apenas um ano letivo, num contexto de sete mil unidades escolares. (BORGES, 2001, p. 314).

De qualquer forma, o que se nota é que as modificações advindas da implantação da Escola Padrão não alteraram a concepção de educação no tocante à incorporação de elementos das pedagogias do "aprender a aprender".

No artigo "O construtivismo e o ensino de ciências", publicado nessa gestão, os autores apresentam a concepção construtivista de conhecimento e discutem a importância do ensino ser dirigido pelos interesses do aluno, que devem ser suscitados pelo professor por meio de vivências, especialmente nas séries iniciais do $1^{\circ}$ grau. Para eles, o ensino de ciências deve "[...] enfatizar a iniciativa da criança, estimular suas ações sobre os objetos e suas observações das reações desses objetos às suas ações." (CARVALHO, LABURÚ, SILVA et al, 1992, p. 71). Por meio de atividades que privilegiem a ação da criança, ela poderia produzir reações e assim, estaria se tornando cada vez mais autônoma em sua busca de explicações e conclusões sobre as relações causais do fenômeno. Além do espontaneísmo pedagógico contido nesse raciocínio, nota-se que a objetividade do conhecimento é relativizada conforme o ponto de vista do experimentador (no caso, as conclusões da criança sobre suas descobertas). Como asseveram os autores:

Ao selecionarmos as atividades de ciências para as primeiras séries estamos naturalmente rejeitando uma série de outras. Ao fazermos isto, temos bem claro para nós que o objetivo dessas atividades não é ensinar um conceito ou dar explicações científicas de forma acabada, mas estamos querendo fornecer oportunidades para que as crianças se envolvam num clima de experimentação, isto é, ajam sobre os objetos que lhes oferecemos buscando estabelecer relações entre o que ela faz e como o objeto reage à sua ação tornem-se cada vez mais autônomas, defendam suas próprias ideias com segurança e respeitem as ideias dos outros colegas caso sejam diferentes das suas. (CARVALHO, LABURÚ, SILVA et al, 1992, p. 71). 
Em primeiro lugar, devemos destacar que esse trecho possibilita enxergar os mecanismos de assimilação-acomodação-adaptação previstos na teoria piagetiana, pois defende que o ensino ofereça situações para a ação da criança, de forma que ela observe a reação do objeto e com isso se adéque aos resultados. Além disso, podemos discutir a questão do papel da escola no acesso às formas mais desenvolvidas do saber objetivo. Para o construtivismo, a realidade não pode ser conhecida em si mesma, pois ela depende de uma construção individual, realizada interiormente por cada sujeito, portanto, saber objetivo é entendido como algo impositivo e inconquistável.

Como afirma Duarte (2010a), será que nós acreditaríamos que a ideia de que o Sol gira em torno da Terra é apenas diferente da afirmação científica de que é a Terra que gira em torno do Sol? Não. Nós sabemos, por meio da ciência, que há uma resposta verdadeira e outra não e que, portanto, não se pode relativizar essa resposta. Para Duarte (2008), tratase de uma ilusão com finalidade de reprodução ideológica do capitalismo a ideia de que a realidade é apenas uma elaboração subjetiva, que permite negociar significados em função de uma ou outra convenção cultural. Nesse sentido, o teor do texto que apresentamos da SEE, mantém seus vínculos aos princípios valorativos do "aprender a aprender", com ênfase na aprendizagem não intencional, voltada aos interesses dos indivíduos, tendo a escola papel de adaptá-los à sociedade como tal. .

Em contraposição a essas ideias, para a pedagogia histórico-crítica, a escola enquanto instituição social é fundamental ao desenvolvimento psíquico da criança por sua função e representatividade na sociedade, pois

[...] as aquisições do desenvolvimento histórico das aptidões humanas não são simplesmente dadas aos homens nos fenômenos objetivos da cultura material e espiritual que os encarnam, mas são aí apenas postas. Para se apropriar destes resultados, para fazer deles as suas aptidões, "os órgãos da sua individualidade", a criança, o ser humano, deve entrar em relação com os fenômenos do mundo circundante através de outros homens, isto é, num processo de comunicação com eles. Assim, a criança aprende a atividade adequada. Pela sua função este processo é, portanto, um processo de educação. (LEONTIEV, 1978, p. 272, grifo do autor).

Ao destinar à escola o papel de transmitir a cultura universal de forma sistematizada e ao professor o papel de garantir, de forma intencional a apropriação do patrimônio humano-genérico, a pedagogia histórico-crítica valoriza o conhecimento, o educador toma papel destacado e assim, proporciona-se ao aluno o domínio daquilo que a burguesia tem se apropriado de forma privada e que deveria ser de todos e não de uma parcela privilegiada da sociedade capitalista. A objeção a essas premissas, como faz o construtivismo, esvazia a educação escolar, toma o professor como figura secundária (que, portanto, não precisa de valorização, seja ela salarial ou de condições de exercício de sua profissão) e acorrenta o aluno aos conhecimentos mínimos necessários para que seja explorado pelo capitalismo.

\section{Os governos de Covas}

No final de 1994, Mário Covas Júnior vence as eleições estaduais pelo Partido da Social Democracia Brasileira (PSDB) para governar o Estado no período de 1995 a 1998, sendo reeleito para um segundo mandato de 1999 a 2002. 
O programa "Reorganização das Escolas da Rede Pública", implantado por essa gestão, estruturava a reforma do ensino em três eixos básicos (DUARTE, 2007): a racionalização da rede administrativa (reorganização e informatização da rede), a mudança no padrão de gestão (delegação de competências administrativas e financeiras às delegacias de ensino) e a melhoria da qualidade do ensino (com iniciativas no campo pedagógico, de avaliação e na carreira docente).

Destacam-se entre as inovações desse período o regime de progressão continuada, a flexibilização curricular, o projeto das salas-ambientes, a introdução de mudanças na concepção de avaliação, cujo mecanismo mais importante foi a instauração do SARESP, a reorganização da rede física escolar e o estabelecimento de um novo plano de carreira para os professores. (DUARTE, 2007, p. 71).

O documento que apresentaremos desse governo é "A Escola de Cara Nova: programa de educação continuada" (SÃO PAULO, 1997). Trata-se de uma publicação que apresenta a síntese do projeto de educação continuada da SEE, desenvolvido entre 1996 e 1997 com o objetivo de garantir um "novo modelo de formação". Como enfatiza o documento, diversos programas de desenvolvimento profissional vinham sendo realizados, mas a despeito disso a educação não apresentava melhorias significativas. Assim, a proposta era que se fizesse o rompimento com "formas tradicionais de capacitação".

O texto procura responder porque são ineficazes essas formas de capacitação indicando a inadequação dos cursos que eram ministrados às reais necessidades dos professores; a inexistência de acompanhamento sistemático de avaliação do impacto dessas capacitações em sala de aula e a predominância da forma de cursos, que deveria a partir de então ser substituída por "[...] planos integrados de ação educativa no âmbito de suas regiões, que resultem numa progressiva autonomia para as delegacias de ensino e para as próprias escolas, acarretando melhoria no desempenho de seus alunos." (SÃO PAULO, 1997, p. 6). O documento explica o insucesso das formações pela "[...] ausência de ênfase em metodologias vivenciais, passíveis de serem desenvolvidas em sala de aula [...]" e critica também o fato de que nos cursos estaria ocorrendo "[...] abordagem de temáticas excessivamente teóricas, desligadas da prática do professor, ou exclusivamente práticas, sem embasamento teórico e/ou relação com o desenvolvimento curricular. (SÃO PAULO, 1997, p. 6).

É preciso assinalar que a SEE não deixou de produzir material para suporte teórico, nesse período e em outros, mas não cogita a relação da qualidade de seu próprio material com a suposta falta de embasamento teórico. Vale sublinhar também, que os materiais pedagógicos "[...] adquiridos ou produzidos pelas instituições capacitadoras, com a finalidade de fundamentar as discussões coletivas dos profissionais envolvidos [...]" deveriam ter

[...] como referenciais técnico-metodológicos as publicações elaboradas pela SEE que apresentam as diretrizes da política educacional, o novo modelo pedagógico de funcionamento das escolas e os parâmetros para a organização e desenvolvimento do currículo escolar. (SÃO PAULO, 1997, p. 15).

Não seria essa uma contradição? Se o objetivo da capacitação era formular um novo modelo, ele não deveria ser pautado por novas concepções teórico-metodológicas? $\mathrm{O}$ que se pode concluir é que, na verdade, como vimos argumentando, a SEE não teve, desde seu primeiro governo democrático (1983), nenhuma intenção de mudar seu ideário 
educacional, mesmo diante dos resultados insatisfatórios alcançados, apresentados pela própria Secretaria.

O modelo de formação proposto pelo documento visa contemplar o processo "açãoreflexão-ação", que se justifica na preocupação de que as capacitações não se esgotem fora da prática profissional. Portanto, as ações desse programa de formação continuada deveriam se organizar em atividades coletivas de reflexão sobre a realidade educacional e ações realizadas no local de trabalho do profissional (professor, diretor, coordenador, supervisor de ensino etc.), com seus pares, “[...] visando integrar a prática profissional e o conhecimento sistematizado, levantando novos dados extraídos de sua própria vivência, e que serão objeto de análise e reflexão nas discussões coletivas." (SÃO PAULO, 1997, p. 9).

Os pressupostos desse tipo de capacitação são coerentes com as ideias de Donald Schön, fundamentadas nos estudos de John Dewey. Para Facci (2004), o "professor reflexivo" de Schön é um profissional em contínua formação, que é, na verdade, autoformação, pois confronta seus saberes com sua prática (reflexão na e sobre a prática), sendo esse um processo coletivo no qual são importantes as trocas de experiências. Parece que na perspectiva desses estudos, cada sujeito particular, interagindo com outros indivíduos, engendra uma coletividade que, por meio de suas práticas, produzirá o profissional docente.

Notemos que a perspectiva adotada por esse tipo de formação, ao desvalorizar os saberes científicos, reforça a ideia de que a realidade deve ser compreendida em suas especificidades locais, colocando acento negativo naquilo que não está no cotidiano dos professores, ou seja, no conhecimento universal. Esse entendimento, presente desde as administrações anteriores, permanecerá nas seguintes, como veremos a seguir.

\section{Os governos de Alckmin}

Com a morte de Mário Covas assume o vice-governador Geraldo José Rodrigues Alckmin Filho (período de 03/2001-12/2002). Posteriormente, Geraldo Alckmin vence o pleito estadual e permanece no governo por mais quatro anos.

Nessa gestão, diversos projetos foram implantados, entre eles: Escola da Juventude, Escola da Família, Escola de Tempo Integral e ainda outros diretamente voltados à formação de gestores e professores: Pró-Gestão, Gestão Escolar e Tecnologias, Teia do Saber, Ensino Médio em Rede, programa Bolsa Mestrado e orientações técnicas dadas nas oficinas pedagógicas por meio de teleconferências e por intermédio dos Assistentes Técnicos Pedagógicos (ATPs). (DUARTE, 2007).

Faremos aqui considerações sobre um texto do módulo do curso de formação de professores alfabetizadores "Letra e Vida", oferecido aos professores da rede estadual de ensino de São Paulo a partir de 2003.

Uma das defesas presentes em todos os módulos, é de que as atividades desenvolvidas com os alunos estejam voltadas aos seus interesses e relacionadas ao cotidiano. O texto de Daniel Pennac, contido no módulo 1, denominado "Direitos imprescritíveis do leitor", é exemplo disso. O autor lista dez direitos que são negados a quem está se iniciando no universo da leitura. São eles:

1. O direito de não ler.

2. O direito de pular páginas.

3. O direito de não terminar um livro.

4. $\mathrm{O}$ direito de reler. 

5. O direito de ler qualquer coisa.
6. O direito ao bovarismo.
7. O direito de ler em qualquer lugar.
8. O direito de ler uma frase aqui e outra ali.
9. O direito de ler em voz alta.
10. O direito de calar. (PENNAC, 2005, M1U4T6, p. 1).

$\mathrm{O}$ autor justifica essa enumeração afirmando que nós não lemos continuamente, muitas vezes trocamos um bom livro por um filme ruim e que nossos "[...] períodos de leitura se alternam muitas vezes com longas dietas, onde até a visão de um livro desperta os miasmas da indigestão." (PENNAC, 2005, M1U4T6, p. 1). Por isso, por que negar ao jovem leitor, o direito de ler qualquer coisa, de qualquer jeito, em qualquer lugar ou simplesmente, não ler?

Prossegue o autor, asseverando que uma grande quantidade de indivíduos respeitáveis, mesmo diplomados, não têm o hábito de ler e que

\begin{abstract}
Nem por isso eles são menos frequentáveis, são mesmo muito agradáveis de se frequentar (pelo menos não perguntam à queima roupa nossa opinião sobre o último livro que lemos, nos livram de suas reservas irônicas sobre nosso romancista preferido e não nos consideram como alienados por não nos termos precipitado sobre o último Tal, que acaba de sair pela Editora Coisa e ao qual o crítico Duchmole fez os maiores elogios). Eles são tão "humanos" quanto nós, perfeitamente sensíveis às desgraças do mundo, atentos aos "direitos humanos" e preocupados em respeitá-los dentro da sua esfera de influência pessoal, o que já é muito. Mas eles não lêem. Direito deles. (PENNAC, 2005, M1U4T6, p. 2).
\end{abstract}

Pennac encerra seu artigo assinalando que o dever da educação é ensinar as crianças a ler, iniciá-las na literatura "[...] fornecendo-lhes meios de julgar livremente se elas sentem ou não a 'necessidade dos livros'." (PENNAC, 2005, M1U4T6, p. 2).

Para além das ironias dirigidas à cultura erudita (como se entender de literatura fosse algo esnobe), declarações como essas têm implicações um tanto graves para a formação humana. Nelas está presente a consideração de que cada sujeito deve buscar seus próprios caminhos (o indivíduo vai descobrir se gosta ou não de ler), como se suas histórias pessoais pudessem ser definidas somente a partir de seus planos, o que é de um idealismo nefasto. Ademais, se o aluno não se apropriar dos clássicos da literatura, se preferir assistir um filme ruim, isso não faz dele uma pessoa pior (há um conteúdo moral bastante forte nessa afirmação), apenas diferente. Entretanto, devemos questionar: quem será responsável pelo empobrecimento de seu desenvolvimento? Ele mesmo! Se isso lhe trouxer consequências, a culpa é sua, afinal, foi ele que "escolheu" não ler.

Sublinhemos que esse desmonte em relação ao conhecimento, nesse caso, literário, encontra amparo nos pressupostos piagetianos de que a atividade educativa deve ser baseada na adaptabilidade, na assimilação espontânea e na satisfação das necessidades dos sujeitos, nada mais que isso.

Ferreira e Duarte (2009), discutindo o papel da arte e em seu interior, a função da literatura na formação humana, asseveram que ela é uma manifestação não-natural, que precisa de atos intencionais que engendrem necessidades complexas nos indivíduos, 
produzindo a sensibilidade humana, o que não é possível por meio de um ensino esvaziado de conteúdos estéticos. Destarte, argumentam os autores que

[...] a verdadeira formação dos sentidos e das sensibilidades humanas, na concepção de Marx, é um processo dialético desenvolvido ao longo da história social e subordinado as condições objetivas de cada momento histórico. A efetiva formação dos sentidos e sensibilidades por meio da vivencia estético-literária é, sem dúvidas, uma via vultosa para emancipação e para liberdade humana. (FERREIRA e DUARTE, 2009, p. 6).

Assim, o compromisso da educação deve repousar no ensino da riqueza cultural humana, como propõe a pedagogia histórico-crítica, de forma que "[...] o aluno entre em contato com o patrimônio literário de mais alto grau de elaboração humana. Essa é uma responsabilidade a qual uma educação emancipadora não se pode furtar." (FERREIRA e DUARTE, 2009, p. 6).

\section{O governo Serra}

José Serra, também pertencente aos quadros do PSDB, foi eleito para o governo do Estado no período de 2007 a 2010. Renunciou ao cargo em 2 de abril de 2010 para se candidatar à Presidência da República, assumindo o governo paulista seu vice, Alberto Goldman.

Essa administração teve como marca o estabelecimento de novas propostas curriculares e o Programa "Ler e Escrever", instaurado com o objetivo de "[...] reverter o quadro de analfabetismo e de alfabetização precária dos alunos do Ciclo I do Ensino Fundamental, da Rede Estadual de Ensino." (SÃO PAULO, 2007).

A concepção construtivista permanece nos livros do "Ler e Escrever", composto de guias para o professor e material do aluno. As proposições de língua portuguesa (de todas as séries) giram em torno do trabalho com contos, fábulas, listas, lendas, canções, quadrinhas, poemas, piadas, textos instrucionais, jornalísticos e científicos, parlendas e adivinhas. Embora a lista pareça ampla, devemos fazer algumas observações sobre seu alcance.

No guia da $2^{\mathrm{a}}$ série, uma das atividades propostas é ensinar os alunos a usar o dicionário por meio de um texto científico. Afirma o documento que recorrer ao dicionário "[...] é uma forma de resolver problemas imediatos, relacionados à leitura ou à escrita" (SÃO PAULO, 2008, p. 107, grifo nosso). Assim, nessa atividade os discentes devem buscar no dicionário palavras com o mesmo significado (o termo sinônimo não é mencionado) para os vocábulos destacados no texto.

Veja-se que com isso o texto científico na verdade é só um pano de fundo para as questões de língua portuguesa. Além disso, esse gênero é minoritário nas proposições de atividades de todas as séries e sempre aparece vinculado a um "projeto didático". Aliás, é bom sublinhar que projetos temáticos são o ponto forte dos livros do "Ler e Escrever", especialmente a partir da $3^{a}$ série. O que se observa nesse tipo de organização de conteúdos, é que os conhecimentos ficam dispersos, são trabalhados de forma reduzida e sem continuidade de um ano para outro ou mesmo de um projeto para outro dentro da mesma série.

Façamos mais alguns destaques sobre o direcionamento dos conteúdos às suas utilidades pragmáticas e particulares. No guia da $3^{\text {a }}$ série se propõe uma sequência de 
atividades envolvendo a elaboração de "cartas de leitor". O material justifica a sugestão desse trabalho afirmando que

\begin{abstract}
Atualmente sabemos que não basta aprender a ler e escrever para ser um leitor competente de todos os gêneros que circulam no mundo da escrita. Tanto a competência leitora quanto a escritora se faz pelo uso de uma diversidade de gêneros a partir das necessidades de comunicação postas no meio em que os indivíduos vivem. (SÃO PAULO, 2009, p. 165, grifo nosso).
\end{abstract}

Também no guia da $2^{\mathrm{a}}$ série observamos essa ligação com o cotidiano quando o material se refere à importância da atividade de estudo.

\begin{abstract}
A necessidade de aprender a estudar, para as crianças, não é apenas uma condição para a continuidade da vida escolar. É essencial também para o futuro exercício profissional, pois a capacidade de se atualizar continuamente se mostra vital no mundo atual, tendo em vista a rapidez com que surgem novas informações. E cabe à escola ensinar as práticas associadas ao estudo, particularmente à leitura e à produção de textos de divulgação científica. Tais práticas passam a ganhar cada vez mais espaço à medida que se avança na escolaridade, em textos associados às áreas de História, Geografia a e Ciências Naturais. (SÃO PAULO, 2008, p. 115, grifo nosso).
\end{abstract}

Destaquemos que há uma contradição nessa última afirmação. Se os textos científicos são minoria nos guias e considerando que os componentes curriculares de história, geografia e ciências inexistem nos anos iniciais $\left(1^{\circ}\right.$ ao $\left.3^{\circ}\right)$ e são contemplados em apenas $10 \%$ da carga horária dos dois últimos anos $\left(4^{\circ}\right.$ e $\left.5^{\circ}\right)$, como se espera que eles "ganhem espaço" na medida em que se avança na escolaridade?

O que concluímos da análise desses livros, é que os conteúdos são esparsos, desconexos, com pouca profundidade e visam conhecimentos particulares em detrimento daqueles universais. Della Fonte nos auxilia a compreender as consequências que isso tem para a formação dos indivíduos. Afirma a autora que

Ao abrir mão de qualquer princípio universal, aniquila-se a base para a defesa da diversidade e da pluralidade [...]. Além disso, podemos pensar nos impasses políticos que a noção de um sujeito fluido e fragmentado traz: impede a constituição de laços de solidariedade para além de resistências locais e, assim, mina ações coletivas amplas. A dispersão das pessoas em comunidades e grupos de interesses arrefece o poder de pressão e deixa o Estado capitalista numa posição confortável. (DELLA FONTE, 2003, p. 5).

Na mesma direção, Duarte (2006a) explica que para o pós-modernismo, um projeto educativo orientado pela transmissão e apropriação da cultura universal (universalização da riqueza material e intelectual) seria considerado reacionário, tradicionalista e etnocêntrico. $\mathrm{O}$ adequado para os pós-modernos seria o relativismo cultural. Porém, para este autor " [...] 
é um equívoco considerar-se etnocêntrica a transmissão universalizada da ciência e da arte pela escola e [...] é também um equívoco considerar-se que o relativismo cultural favoreça o livre desenvolvimento dos indivíduos." (DUARTE, 2006a, p. 616).

\section{Considerações finais}

Nos amparamos na pedagogia histórico-crítica para justificar a defesa de outra compreensão do que seja o conhecimento, o aluno e o professor, diferente daquela fundamentada no construtivismo. Entendemos que o conhecimento resulta das objetivações humanas e, como tal, deve ser transmitido às novas gerações, para que estas, ao se apropriarem do patrimônio humano-genérico, possam constituir em cada indivíduo singular, uma segunda natureza, de origem social (SAVIANI, 2003). Sendo assim, fica esclarecido que o aluno é o sujeito a ser formado, ao qual devem se dirigir as ações que promovam o desenvolvimento de suas mais elevadas potencialidades, porque o ser humano, diferentemente dos animais, é um ser que produz necessidades cada vez mais complexas, na medida do seu desenvolvimento. Por isso Marx (1984, p. 178, grifo do autor) afirma que o homem "[...] rico é simultaneamente o homem necessitado de uma totalidade de manifestação humana de vida".

Para proporcionar aos indivíduos a apropriação da cultura, que lhes permitirá serem cada vez mais "necessitados", é indispensável a participação daquele que já apreendeu o patrimônio cultural. Na escola, essa é a figura do professor, pois dirige o desenvolvimento psicológico do aluno, colaborando na formação das funções psicológicas superiores, especificamente humanas, de procedência social. Ainda que a educação escolar não transforme por si mesma a sociedade, ela pode contribuir decisivamente na articulação da luta mais ampla por essa transformação, desde que não esteja alinhada a pedagogias comprometidas com a conservação do capitalismo.

O que pudemos analisar nos documentos da SEE é sua filiação a uma concepção teórica que mantém vínculos com o neoliberalismo e pós-modernismo, que em lugar de possibilitar a apropriação da riqueza material e intelectual humana, ocasiona a preparação do indivíduo para a exploração capitalista.

O governo paulista elaborou material didático e ofereceu cursos em suas consecutivas administrações. Sempre se apoiou no discurso da inovação, do alcance de melhores resultados e de atendimento às "demandas sociais". Não se pode perder de vista que a produção e circulação desses materiais funcionam como interventores sobre a prática pedagógica, inclusive seduzindo os professores para que acreditem que não aderir às pedagogias do "aprender a aprender" significa permanecer à margem das mais avançadas formas de educação.

Se podemos afirmar que na somatória das administrações do PMDB e PSDB (1983-2010), o construtivismo norteia o ensino estadual paulista há 27 anos e levarmos em conta que o governo de 2011-2014, será de Geraldo Alckmin (PSDB) novamente, podemos suspeitar que em breve será possível afirmar que não houve mudanças nas orientações políticas e pedagógicas da SEE em mais de 30 anos!

Reforça essa impressão, o fato de que o atual Secretário-Adjunto da SEE é João Cardoso Palma Filho, coordenador da CENP na década de 1980, nos primórdios da adoção do construtivismo pela rede de ensino de São Paulo. Também podemos mencionar que Maria Helena Guimarães de Castro, Secretária da Educação na gestão de Serra, presidiu o Instituto Nacional de Estudos e Pesquisas Educacionais (INEP) entre 1995 e 2002, quando Paulo Renato Costa Souza era Ministro da Educação (governo de Fernando Henrique Cardoso - PSDB). Este, por sua vez, foi Secretário da Educação em São Paulo na 
gestão de Montoro durante a implantação do $\mathrm{CB}$, retornando ao cargo para substituir sua colega Maria Helena Guimarães de Castro no governo de José Serra. Parece uma "dança das cadeiras" na qual a educação pública estadual paulista é tratada como brincadeira de criança...

Assim, entendemos que se faz necessário continuar a desvelar pedagogias que mantenham vínculos com pressupostos que mantêm os indivíduos alijados de sua possibilidade máxima de desenvolvimento e que só assim poderemos, como postula a pedagogia histórico-crítica, encontrar, no interior da escola, espaço para o objetivo de uma luta maior, a superação da sociedade capitalista e sua substituição pela sociedade comunista.

\section{Referências}

APOLINÁRIO, M. Metas do Ideb: por que são tão tímidas? Jornal Virtual. Humana Editorial. Ano 8, n. 175, julho de 2010. Disponível em: http://meb.zarinha.com.br/2010/07/25/metas-do-ideb-por-que-tao-timidas/. Acesso em 14 de agosto de 2010.

ARCE, A. A pedagogia na "era das revoluções": uma análise do pensamento de Pestalozzi e Froebel. Campinas-SP: Autores Associados, 2002.

BECKER, F. Epistemologia do professor: o cotidiano da escola. Petrópolis-RJ: Vozes, 1993.

BITAR, M. S. A política educacional paulista nos doze anos de governança do PMDB: 1983 a 1994. Dissertação de Mestrado. Universidade Estadual de Campinas. Instituto de Economia. Campinas, 2003.

BORGES, Z. P. A política educacional do Estado de São Paulo durante os governos do PMDB (1983-1994): a proposta partidária e sua execução. Tese de Doutorado. Universidade Estadual de Campinas. Faculdade de Educação. Campinas, 2001.

BRASIL. Ministério da Educação. Instituto Nacional de Estudos e Pesquisas Educacionais Anísio Teixeira. SAEB - 2005 - primeiros resultados: médias de desempenho do SAEB/2005 em perspectiva comparada. Brasília: MEC/INEP, 2007.

CARCANHOLO, M. D. Neoliberalismo e Consenso de Washington: a verdadeira concepção de desenvolvimento do governo FHC. In: MALAGUTI, M. L.;

CARCANHOLO, R.; CARCANHOLO, M. D. (Orgs.). Neoliberalismo: a tragédia do nosso tempo. São Paulo: Cortez, 1998. p. 15-35.

CARVALHO, A. M. P.; LABURÚ, C. E.; SILVA, D. et al. O construtivismo e o ensino de ciências. In: SÃO PAULO (Estado). Secretaria da Educação. Ciências na escola de $\mathbf{1}^{\mathbf{0}}$ grau: textos de apoio a proposta curricular. Coordenadoria de Estudos e Normas Pedagógicas. São Paulo: SE/CENP, 1991. p. 63-73.

CARVALHO, D. P. Planejamento escolar: visão possível. Tese de Doutorado. Universidade Estadual Paulista, Faculdade de Filosofia e Ciências. Marília, 1999.

CARVALHO, S. R. Políticas neoliberais e educação pós-moderna no ensino paulista. Dissertação de Mestrado. Universidade Estadual Paulista, Faculdade de Ciências e Letras. Araraquara, 2010. 
CASADO, M. I. M. O sistema de ciclos e a jornada de trabalho do professor do Estado de São Paulo. Dissertação de Mestrado. Universidade Metodista de Piracicaba. Faculdade de Ciências Humanas. Piracicaba, 2006.

CRAIDY, C. M.; GROSSI, E. P.; FIALHO, N. R. M. Uma proposta didática para alfabetização de crianças das classes populares. Revista Brasileira de Estudos Pedagógicos. v. 64. n. 148. set/dez, 1983. p. 208-216.

DELLA FONTE, S. S. Filosofia da Educação e agenda pós-moderna. Anais da 26a. Reunião Anual da ANPED, Poços de Caldas, 2003. p. 1-16.

DUARTE, N. O debate contemporâneo das teorias pedagógicas. 2010a. No prelo.

Conhecimento tácito e conhecimento escolar na formação do professor (por que Donald Schön não entendeu Luria). In: DUARTE, N.; DELLA FONTE, S. S. Arte, conhecimento e paixão na formação humana: sete ensaios de pedagogia históricocrítica. Campinas: Autores Associados, 2010b.

Por que é necessário uma análise crítica marxista do construtivismo? In:

LOMBARDI, J. C. SAVIANI, D. (Orgs.). Marxismo e educação: debates contemporâneos. 2. ed. Campinas - SP: Autores Associados, 2008. p. 203-221.

A contradição entre universalidade da cultura humana e o esvaziamento das relações sociais: por uma educação que supere a falsa escolha entre etnocentrismo ou relativismo cultural. Educação e Pesquisa. São Paulo, v.32, n.3, set./dez, 2006a. p. 607618.

Vigotski e o "aprender a aprender": crítica às apropriações neoliberais e pósmodernas da teoria vigotskiana. 4. ed. Campinas - SP: Autores Associados, 2006b.

(Org.). Crítica ao fetichismo da individualidade. Campinas-SP: Autores Associados, 2004.

Sociedade do conhecimento ou sociedade das ilusões: quatro ensaios críticodialéticos em filosofia da educação. Campinas-SP: Autores Associados, 2003.

O Construtivismo seria pós-moderno ou o pós-modernismo seria construtivista? (análise de algumas ideias do "construtivismo radical "de Ernest Von Glasersfeld). In: DUARTE, N. (Org.). Sobre o construtivismo: contribuições a uma análise crítica. Campinas-SP: Autores Associados, 2000. p. 87-106.

Concepções afirmativas e negativas sobre o ato de ensinar. Caderno CEDES. O professor e o ensino: novos olhares. Campinas, n. 44, 1998. p. 85-106.

DUARTE, R. C. O professor coordenador das escolas públicas estaduais paulistas: Análise das Condições de Trabalho e a Construção do Projeto Político-Pedagógico. Dissertação de Mestrado. Universidade Estadual Paulista. Faculdade de Ciências e Letras. Araraquara, 2007.

DURAN, M. C. G.; ALVES, M. L.; PALMA FILHO, J. C. Vinte anos da política do ciclo básico na rede estadual paulista. Cadernos de Pesquisa. v. 35, n. 124, jan./abr. 2005. p. 83-112,.

EIDT, N. M. A relação entre a atividade de pensamento e a apropriação da cultura na psicologia de A. N. Leontiev e sua incorporação a dissertações e teses em educação no Brasil no período de 1987 a 2004. Doutorado em Educação Escolar. Universidade Estadual Paulista "Júlio de Mesquita Filho", Araraquara, 2009. 
FACCI, M. G. D. Valorização ou esvaziamento do trabalho do professor? Um estudo crítico-comparativo da teoria do professor reflexivo, do construtivismo e da psicologia vigotskiana. Campinas-SP: Autores Associados, 2004.

FERREIRA, N. B. P.; DUARTE, N. Estética marxista, educação e emancipação humana: implicações para o ensino de literatura. In: MENDONÇA, S. G. L.; SILVA, V. P. (Orgs.). Socialismo e educação na América Latina: coletânea de textos do IV EBEM - Encontro Brasileiro de Educação e Marxismo. São José do Rio Preto, 13 a 16 de julho de 2009. Marília: Oficina Universitária Unesp, 2009. p. 1-8.

FURTADO, A. C. Por uma história das práticas de formação docente: um estudo comparado entre duas escolas normais de Ribeirão Preto-SP (1944-1964). Tese de Doutorado. Universidade de São Paulo. Faculdade de Educação. São Paulo, 2007.

GARCIA, R. L. A qualidade comprometida e o compromisso da qualidade. ANDE. Revista da Associação Nacional de Educação de São Paulo, 1 (3), 1982. In: SÃO PAULO (Estado) Secretaria de Educação. Projeto "Capacitação de recursos humanos para o ensino de $1^{\circ}$ grau”" (Treinamento: Formação de monitores de alfabetização). Coordenadoria de Estudos e Normas Pedagógicas. São Paulo: SE/CENP, 1983.

KRAWCZYK, N.; BRUNSTEIN, R. Sindicalismo e governo: uma agenda para o diálogo sobre a reforma educativa. O caso do Estado de São Paulo/Brasil. Disponível em: http://www.lpp-uerj.net/olped/documentos/conflitos/area_trabalho/0030.pdf. Acesso em: 16 de agosto de 2007.

LEONTIEV, A. O desenvolvimento do psiquismo. Lisboa: Livros Horizonte, 1978.

LIMA, A. B.; VIRIATO, E. O. As políticas de descentralização, participação e autonomia: desestatizando a educação pública. In: REUNIÃO ANUAL DA ANPEd, 23.; GT Estado e Política Educacional no Brasil, 2000, Caxambu. Anais... Rio de Janeiro: Associação Nacional de Pós-graduação e Pesquisa em Educação, 2000. Disponível em: http://www.anped.org.br/reunioes/23/textos/0523t.PDF.

MARSIGLIA, A. C. G. Um quarto de século de construtivismo como discurso pedagógico oficial na rede estadual de ensino paulista: análise de programas e documentos da Secretaria de Estado da Educação no período de 1983 a 2008. Tese de Doutorado. Universidade Estadual Paulista. Faculdade de Ciência e Letras. Araraquara, 2011.

MARTINS, L. M. Da formação humana em Marx à crítica da pedagogia das competências. In: DUARTE, N. (Org.). Crítica ao fetichismo da individualidade. Campinas-SP: Autores Associados, 2004. p. 53-73.

MARX, K. A consciência revolucionária da história (Manuscritos econômico-filosóficos de 1844). In: FERNANDES, F. (Org.) Marx e Engels: História. 2. ed. São Paulo: Ática. 1984. p. 146-181.

MAZZEU, L. T. B. Formação continuada de professores: uma análise crítica sobre as perspectivas oficiais de capacitação docente. Dissertação de Mestrado. Faculdade de Ciências e Letras, Universidade Estadual Paulista, Araraquara, 2007.

MINTO, L. W. Globalização, transição democrática e educação (inter)nacional (1984...). Campinas: Gráfica FE/Unicamp; HISTEDBR, 2006 (CD-ROM).

MORAES, M. C. M. Os "pós-ismos” e outras querelas ideológicas. Perspectiva, Florianópolis, v. 14, n. 25, jan./jun.1996. p. 45-60. Disponível em: 
http://www.periodicos.ufsc.br/index.php/perspectiva/article/view/10856/10334. Acesso em 27 de dezembro de 2010.

NÓBREGA, M. L. S. Escola-padrão: Autonomia e Gestão Democrática. Dissertação de Mestrado. Universidade Estadual de Campinas. Faculdade de Educação. Campinas, 1999.

OLIVEIRA, S. R. F. Formulação de políticas educacionais: um estudo sobre a Secretaria de Educação do Estado de São Paulo (1995-1998). Dissertação de Mestrado. Universidade Estadual de Campinas. Faculdade de Educação. Campinas, 1999.

PALMA FILHO, J. C. A política educacional do Estado de São Paulo no período de 19832008. X Congresso Estadual Paulista Sobre Formação de Educadores - Formação de professores e a prática docente: os dilemas contemporâneos. São Paulo: Fundação Unesp. 2009. p. 6053-6065.

PARAGUASSÚ, L. PISA 2006 - Para o MEC, SP puxou notas para baixo. Site Todos pela Educação. Fonte: O Estado de São Paulo. Notícia de 05/12/2007. Disponível em: http://todospelaeducacao.org.br/comunicacao-e-midia/educacao-na-midia/453/pisa-2006--para-o-mec-sp-puxou-notas-para-baixo. Acesso em 20 de dezembro de 2010.

PARAGUASSÚ, L.; MANDELLI, M. São Paulo fica em $7^{\circ}$, atrás de ES e Região Sul. Site Todos pela Educação. Fonte: O Estado de São Paulo. Notícia de 08/12/2010.

Disponível em: http://www.todospelaeducacao.org.br/comunicacao-e-midia/educacao-namidia/12292/sao-paulo-fica-em-7-atras-de-es-e-regiao-sul. Acesso em 20 de dezembro de 2010.

PENNAC, D. Direitos imprescritíveis do leitor. In: SÃO PAULO (Estado). Letra e Vida: programa de formação de professores alfabetizadores. Coletânea de textos. Módulo 1. Secretaria da Educação. Coordenadoria de Estudos e Normas Pedagógicas. São Paulo: SE/CENP, 2005. M1U4T6, p. 1-2.

PEREIRA, G. E. A política de conciliação: os intelectuais e o governo Montoro.

Dissertação de Mestrado. Universidade Estadual de Campinas. Faculdade de Educação. Campinas, 1994.

PEREIRA, M. F. R. Dois sentidos para a educação na década de 1980: democracia e cidadania/ implicações históricas. In: LOMBARDI, J. C.; SAVIANI, D. NASCIMENTO, M. I. M. (Org.). Navegando pela história da educação brasileira. Campinas: Graf. FE: HISTEDBR, 2006. p. 1-29. Disponível em:

http://www.histedbr.fae.unicamp.br/navegando/artigos_frames/artigo_071.html. Acesso em 14 de novembro de 2008.

PEREZ, J. R. R. A política educacional do Estado de São Paulo: 1967-1990. Tese de Doutorado. Universidade Estadual de Campinas. Faculdade de Educação. Campinas, 1994.

ROSSLER, J. H. Sedução e alienação no discurso construtivista. Campinas-SP: Autores Associados, 2006.

ROSSLER, J. H. Construtivismo e alienação: as origens do poder de atração do ideário construtivista. In: DUARTE, N. (Org.). Sobre o construtivismo: contribuições a uma análise crítica. Campinas-SP: Autores Associados, 2000. p. 3-22.

SALA, M. Socialização do conhecimento ou sociabilidade adaptativa: trabalho e educação diante das transformações do capitalismo contemporâneo. Dissertação de Mestrado. Universidade Estadual Paulista. Faculdade de Ciências e Letras. Araraquara, 2009. 
SÃO PAULO (Estado) Secretaria de Educação. Ler e escrever: guia de planejamento e orientações didáticas; professor $-3^{\mathrm{a}}$ série. Fundação para o Desenvolvimento da Educação. Concepção e elaboração: Angela Maria da Silva Figueiredo... [e outros]. São Paulo: FDE, 2009.

Ler e escrever: guia de planejamento e orientações didáticas; professor $-2^{\mathrm{a}}$ série. 2. ed. v. 1. Fundação para o Desenvolvimento da Educação. Adaptação do material original: Claudia Rosenberg Aratangy, Ivânia Paula Almeida, Rosalinda Soares Ribeiro de Vasconcelos. São Paulo: FDE, 2008.

Comunicado SE de 19 de dezembro de 2007. Orienta a implantação do Programa Ler e Escrever nas escolas da rede pública estadual, 2007.

A escola de cara nova: programa de educação continuada. Secretaria da Educação. Coordenadoria de Estudos e Normas Pedagógicas. São Paulo: SE/CENP, 1997.

Isto se aprende com ciclo básico. Secretaria da Educação. Coordenadoria de Estudos e Normas Pedagógicas. São Paulo: SE/CENP, 1987.

Decreto no 21.833, de 28 de dezembro de 1983. Institui o Ciclo Básico no ensino de $1^{\circ}$ grau das escolas estaduais, 1983a.

Projeto "Capacitação de recursos humanos para o ensino de $1^{\circ}$ grau”" (Treinamento: Formação de monitores de alfabetização). Coordenadoria de Estudos e Normas Pedagógicas. São Paulo: SE/CENP, $1983 b$.

SAVIANI, D. Pedagogia histórico-crítica: primeiras aproximações. 8. ed. Campinas-SP: Autores Associados, 2003.

SILVA. M. A. Anos 80: da transição com "abertura”, mas sem ruptura, do governo burocrático autoritário para o civil. In: LOMBARDI, J. C.; SAVIANI, D. NASCIMENTO, M. I. M. (Org.). Navegando pela história da educação brasileira. Campinas: Graf. FE: HISTEDBR, 2006. p. 1-33. Disponível em:

http://www.histedbr.fae.unicamp.br/navegando/artigos_frames/artigo_067.html. Acesso em 14 de novembro de 2008.

SOUZA, A. N. As políticas educacionais para o desenvolvimento e o trabalho docente. Tese de Doutorado. Universidade Estadual de Campinas. Faculdade de Educação.

Campinas, 1999.

UTSUMI, M. C. Escola-Padrão: avanço na melhoria do ensino? Dissertação de Mestrado. Universidade Estadual de Campinas. Faculdade de Educação. Campinas, 1995.

VERÍSSIMO, M. V. B. et al. Política educacional e o desafio do ensinar e aprender: meandros do processo de inclusão/exclusão. In: NÚCLEOS DE ENSINO. Universidade Estadual Paulista. Pró-reitoria de graduação. p. 444-454. Editora Unesp, 2006. Disponível em: http://www.unesp.br/prograd/PDFNE2004/artigos/eixo8/politicaeducacional.pdf.

Acesso de 28 de fevereiro de 2009.

VILELA, L. R. Uma análise de políticas educacionais no ensino paulistana década de 90. Dissertação de Mestrado. Universidade Estadual de Campinas. Faculdade de Educação. Campinas, 2002.

WEIZ, T. As contribuições da psicogênese da língua escrita e algumas reflexões sobre a prática educativa de alfabetização. In: SÃO PAULO (Estado). Ciclo básico em jornada única: uma nova concepção de trabalho pedagógico - recursos didáticos, sua utilização. v. 


\section{Secretaria da Educação. Coordenadoria de Estudos e Normas Pedagógicas. São Paulo: SE/CENP/FDE, 1988.}

Notas:

${ }^{1}$ Graduada em Pedagogia pela Universidade Estadual Paulista (UNESP), campus de Bauru e Doutora em Educação Escolar pela mesma universidade, campus de Araraquara (bolsista FAPESP). Professora do Centro de Educação da Universidade Federal do Espírito Santo e membro do grupo de pesquisa "Estudos Marxistas em Educação" galvao.marsiglia@gmail.com.

${ }^{2}$ O PISA (Programme for International Student Assessment) é um programa internacional de avaliação, desenvolvido e coordenado pela Organização para Cooperação e Desenvolvimento Econômico (OCDE). No Brasil, a coordenação do programa é feita pelo Instituto Nacional de Estudos e Pesquisas Educacionais "Anísio Teixeira" (INEP). A finalidade do PISA é verificar a eficácia dos sistemas educacionais, avaliando desempenho de alunos na faixa dos quinze anos de idade, em leitura, matemática e ciências.

3 Confira, por exemplo: BITAR, 2003; BORGES, 2001; CARVALHO, 1999; CARVALHO, 2010; CASADO, 2006; DUARTE, 2007; FURTADO, 2007; KRAWCZYK e BRUNSTEIN, 2007; LIMA e VIRIATO, 2000; MAZZEU, 2007; MINTO, 2006; NÓBREGA, 1999; OLIVEIRA, 1999; PALMA FILHO, 2009; PEREIRA, 1994; PEREIRA, 2006; PEREZ, 1994; SALA, 2009; SILVA, 2006; SOUZA, 1999; UTSUMI, 1995; VERÍSSIMO et al, 2006; VILELA, 2002.

${ }^{4}$ Dentre os quais podemos mencionar: ARCE (2002), DUARTE (1998, 2000, 2003, 2004, 2006b, 2008, 2010b), CARVALHO (2010), EIDT (2009), FACCI (2004), MAZZEU (2007), ROSSLER (2006) E SALA (2009)

${ }^{5}$ Carcanholo explica que embora as origens do neoliberalismo possam ser identificadas desde 1944, com a publicação da obra "O caminho da servidão" de Frederick Hayek, sua afirmação se deu no final da década de 1970. O pensamento neoliberal pode ser apresentado segundo quatro premissas: as interações entre os indivíduos (sejam elas econômicas, políticas e/ou sociais) se constituem em função dos interesses próprios de cada um (1). Poderia parecer que assim se desorganizaria a sociedade. Mas isso não ocorre porque esses interesses fazem parte de uma "ordem natural" (2), estabelecida pelo mercado (3). Por isso mesmo, "[...] qualquer interferência nesse mercado é indesejável [...]” (4). (CARCANHOLO, 2002, p. 18).

${ }^{6}$ Para Moraes, o discurso pós-moderno se compõe de uma multiplicidade de interpretações, inclusive inconciliáveis entre si, que exerce influência no mundo contemporâneo talvez "[...] porque procure traduzir no mais das vezes de forma confusa e imprecisa, as mudanças na vida social, política e moral impostas pelas múltiplas formas de reestruturação do capitalismo contemporâneo" (MORAES, 1996, p. 46). Ainda segundo essa autora, o discurso pós-moderno questiona a racionalidade científica como meio de atingir o conhecimento objetivo, sendo, nessa perspectiva, impossível "[...] experienciar este mundo como uma totalidade ordenada e coerente que permite teorizar sobre ele.” (MORAES, 1996, p. 47).

${ }^{7} 1982$ é a data da publicação original do texto de Regina Leite Garcia encartado no material da SEE, cuja coletânea é de 1983.

${ }^{8}$ Comissão Econômica para a América Latina e o Caribe, criada pelo Conselho Econômico e Social das Nações Unidas (ECOSOC).

Recebido em: $\quad$ 24/08/11

Aprovado em: $\quad 15 / 10 / 11$ 